\title{
A Comparative Study on the Motions of a Mooring LNG Ship in Mixed Waves and Long-period Waves Respectively
}

\author{
SHI Xian-ying ${ }^{1, a}$ \\ College of Marine and Civil Engineering, Dalian Ocean University, \\ Liaoning Dalian, 116023 China \\ aashixy003@163.com,
}

\begin{abstract}
Keywords: a mooring (LNG) ship; transverse waves; mixed waves; long-period waves; movement Abstract. A series of physical model experiments have been performed to conduct a comparative study on the motions of a mooring ship. The mooring ship employed in the experiment is an LNG ship under the transverse action of mixed waves and long-period waves respectively. The prerequisite of such a research is that the total energy of the mixed waves should be equal to the long-period waves. The experimental results show that with the increase of low-frequency spectral peak period, the laws of a mooring ship's motion are almost unchanged under the action of three different kinds of bimodal waves. With the variation of spectral peak period, similar situations happened to the laws of the mooring ship's motion under the action of long-period waves. The low-frequency energy of mixed waves has command of the motions of a mooring ship (except the movement of pitch). When is ratio of the low-frequency energy accounts for $20 \%$, the mooring ship's movements in mixed waves will change within the range from 0.5 to 0.6 times of its movements in long-period waves. When the low-frequency energy accounts for $50 \%$, the range will be within 0.7 to 0.8 times. When the low-frequency energy accounts for $80 \%$, the range will be within 0.85 to 0.95 times.
\end{abstract}

\section{Introduction}

It is a very important issue for port design and application to study the motions of a mooring ship. If a mooring ship has a relatively larger motion, the loading and unloading operations of the ship will be affected. Large motions may even break mooring lines, which may lead to greater losses ${ }^{[1-2]}$.

Wave is one of the most important elements of the external environment force acting on the mooring of the ship. According to the different spectral shapes of waves, the waves can be divided into single-peak spectral waves (including the pure wind waves, the pure swells, and the long-period waves) and bimodal spectral waves (the mixed waves: the combined effects of wind waves and swells) ${ }^{[3-5]}$. Substantial observational data analyses of sea waves show that there are few pure wind waves or pure swells on sea. In most cases, swells together with wind waves appear in the form of mixed waves. The spectrum structure of mixed waves is very complex and diverse. In most cases, the spectra of mixed waves are bimodal or multimodal, except for a few cases unimodal. Waves can be divided into two parts by bimodal spectra: the low frequency waves (swells) and the high frequency waves (wind waves).

Many scholars from both home and abroad have recently carried out researches on the motions of mooring ships under the effects of swells and long-period waves: Yang Xian-zhang ${ }^{[6]}$ has studied the effects of long-period waves have upon the motion characteristics of mooring ships. Van der MOLEN et al. ${ }^{[7]}$ has carried out a numerical simulation to a mooring ship's motions induced by long-period waves at Tomakomai Port in Japan. $\mathrm{He}^{[8]}$ has also fulfilled another simulation study on the movements and loads of an LNG mooring ship under the effects of swells at Withnell Bay of Australia. Sakakibara Shigeki et al. ${ }^{[9]}$ has pointed out that long-period waves may induce dramatic motions of any mooring ship. Shi Xian-ying et al. ${ }^{[10]}$ have done series of model tests to study the motion-response characteristics of mooring large natural gas (LNG) ships under the action of long-period waves. Besides, Shi Xian-ying et al. ${ }^{[11]}$ have also studied the law of motion responses of mooring ships under 
the effect of mixed waves. However, there is no comparison study of motion responses of mooring ships in both bimodal spectral mixed waves and unimodal spectral waves.

In this paper, a series of physical model experiments of a mooring ship were performed on a 266,000 $\mathrm{m}^{3}$ LNG ship to investigate and compare its motions under a specific mode of mooring condition but different loading conditions, under the transverse action of waves with the total energy but different in ratios of low-frequency bimodal spectral mixed waves and long-period waves.

\section{Design of the experiment}

\section{Experiment Equipments and Measuring Instruments}

The experiment was conducted in an ocean environmental flume of the State Key Lab of Coastal and Offshore Engineering (SLCOE), Dalian University of Technology, China. The flume is 40 meters long, 24 meters wide and 1.2 meters deep. A piston type wave maker system designed and constructed by SLCOE is installed at one end of the flume, which can generate multidirectional complex waves of both low-frequency and high-frequency according to different test requirements. Wave absorbers are arranged at the other end of the flume to absorb incoming waves to avoid wave reflection.

In the experiment, the wave data were collected by adopting the DS30 system developed by Beijing Research Institute of Water Conservancy Technology (BRIWT). The system can handle up multi-points of wave surface simultaneously and then process data analyses; the measurement of a mooring ship's movements employs the system dedicated to model ship tests with twin CCD optical six-component movement measurement, which is also developed by BRIWT. Such system employs non-contact measurement method to avoid added mass and friction that generated by using the traditional contact one.

\section{Simulations of the Mooring Ship}

The model scale was set 1:60 in accordance with the requirements of Wave Model Test Regulation ${ }^{[12]}$. The experiment was performed on a $266,000 \mathrm{~m}^{3} \mathrm{LNG}$ ship moored to an island berth. The dimensions of the ship are given in Table 1. The model ship was built based on the 3D hull shape definition of a prototype LNG ship at a geometric scale of 1: 60; the weight balance method was used to meet different requirements of load and weight distribution; the LNG ship's main particulars such as its center of gravity, the periods of roll and pitch, etc. were consistent with similar dynamic conditions.

Table 1: Dimensions of the $266,000 \mathrm{~m}^{3} \mathrm{LNG}$ ship

\begin{tabular}{cccc}
\hline Parameters & Unit & Laden & Ballast \\
\hline Length Over all & $\mathrm{m}$ & \multicolumn{2}{c}{345} \\
Length between & $\mathrm{m}$ & \multicolumn{2}{c}{320} \\
Perpendiculars & \multicolumn{3}{c}{55} \\
Breadth & $\mathrm{m}$ & \multicolumn{2}{c}{27.2} \\
Depth & $\mathrm{m}$ & \multicolumn{2}{c}{9.6} \\
Draft & $\mathrm{m}$ & 12 & 9.206 \\
Displacement Volume & $\mathrm{t}$ & 184008 & 14720 \\
height of gravitational center & $\mathrm{m}$ & 24 & 19.2 \\
Natural Period of Roll & $\mathrm{s}$ & 16.24 & 10.83 \\
Natural Period of Pitch & $\mathrm{s}$ & 9.48 & 8.53 \\
\hline
\end{tabular}

\section{Simulations of the Structure of Island Berth}

In the same way, the simulations of the structure of island berth were fulfilled by reducing the prototype on the geometric scale 1:60. The simulation of island berth structure can ensure both the geometric similarity and the similarity of the location of caisson piers, as well as the stability of caisson pier. In addition, the outer shells of the caisson piers are made of wood, filled with gravels and small lead weights inside. The top of each caisson pier is connected with the upper wooden part of the berth, which has formed a unity. A number of weights can be evenly added to the surface of the upper 
structure to make the overall structure of the berth rigid and stable enough. The layout of the berth is shown in Fig. 1.

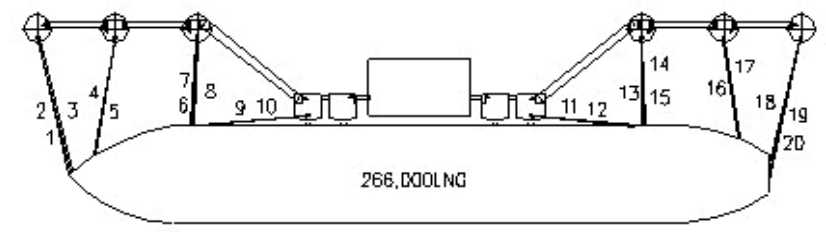

Fig.1 The Berth Layout and the Diagrammatic Illustration of Mooring Patterns of the LNG Ship

\section{Simulations of Mooring Lines}

The mooring lines used for mooring the LNG ship were arranged in a symmetrical way by the number of 3:2:3:2. (See Fig. 1). When the locations of mooring dolphins and positions of the ship's mooring pipes are fixed, the length of lines will automatically satisfy geometric similarity. When simulating the lines, the elastic similar rules of lines should be taken into consideration, and the Wilson formula can be used for calculating the force deformation of the simulating lines. The elastic pieces of steel were adopted to simulate the elasticity of the lines. The Fig. 2 shows the curve graphs of force deformation of forward breast and after breast lines, which manifests good simulation results.

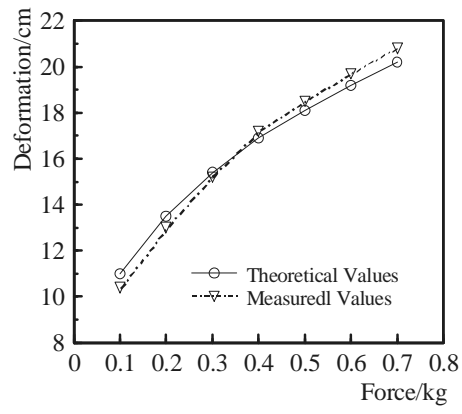

Fig. 2 The Modeling Results of Force Deformation Curves of Breast Lines

\section{Simulations of Fenders}

The main similarity conditions of fenders refer to the similarity of the curves of force deformation and energy deformation of fenders between the prototype and the model. The simulation results shown in Fig. 3 shows that the rubber fenders achieved better results.

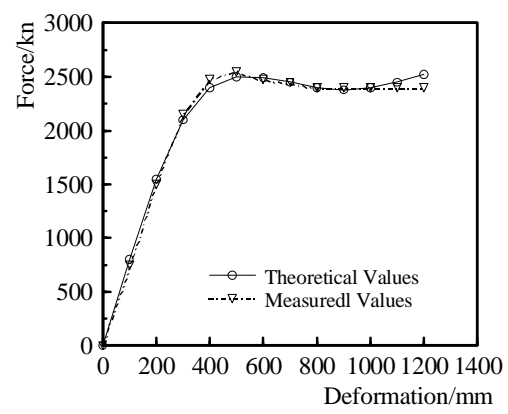

Fig. 3 Force Deformation Curves to the Modeling Results of Fenders

\section{Simulations of Waves}

In the experiment, long-period waves used in the experiment are the ones simulated by the internationally recognized JONSWAP spectrum.

The bimodal spectral mixed waves were generated by a six-spectrum parameter. A six-parameter spectrum can be obtained by combining two three-parameter spectrums in both low and high frequency parts of the waves respectively. The equation is given by 


$$
S(\omega)=\frac{1}{4} \sum_{j} \frac{\frac{4 \lambda_{j}+1}{4}\left(\omega_{m j}^{4}\right)^{\lambda_{j}}}{\Gamma\left(\lambda_{j}\right)} \frac{H_{s j}^{2}}{\omega^{4 \lambda_{j}+1}} \exp \left[-\frac{4 \lambda_{j}+1}{4}\left(\frac{\omega_{m j}}{\omega}\right)^{4}\right] j=1,2
$$

Where $\mathrm{j}=1,2$ represents the low and high frequency parts. There are totally six parameters in the equation, and each change of a parameter, according to the spectrum shape of actual measurement, may minimize the difference between theoretical and measured values of the spectrum.

In the experiments, the significant wave height of long-period waves and the significant wave height of mixed waves were set the same (That is to say, the total energy of the long-period waves and the mixed waves are the same). The period of the high-frequency peak of mixed waves was fixed to $6 \mathrm{~s}$, and the period of low-frequency peak was fixed within the range from 12 to $24 \mathrm{~s}$; the spectral peak period of long-period waves equals to the one of the low-frequency part of mixed waves. The characteristic parameters of long-period waves and mixed waves used for the test are given in Table 2. As shown in Fig. 4, an illustration of the bimodal spectral mixed waves that generated by employing the method of six-parameter spectrum, the theoretical spectrum is seen better fitted the measured one.

Table 2 Characteristic Parameters of Waves in the Experiment

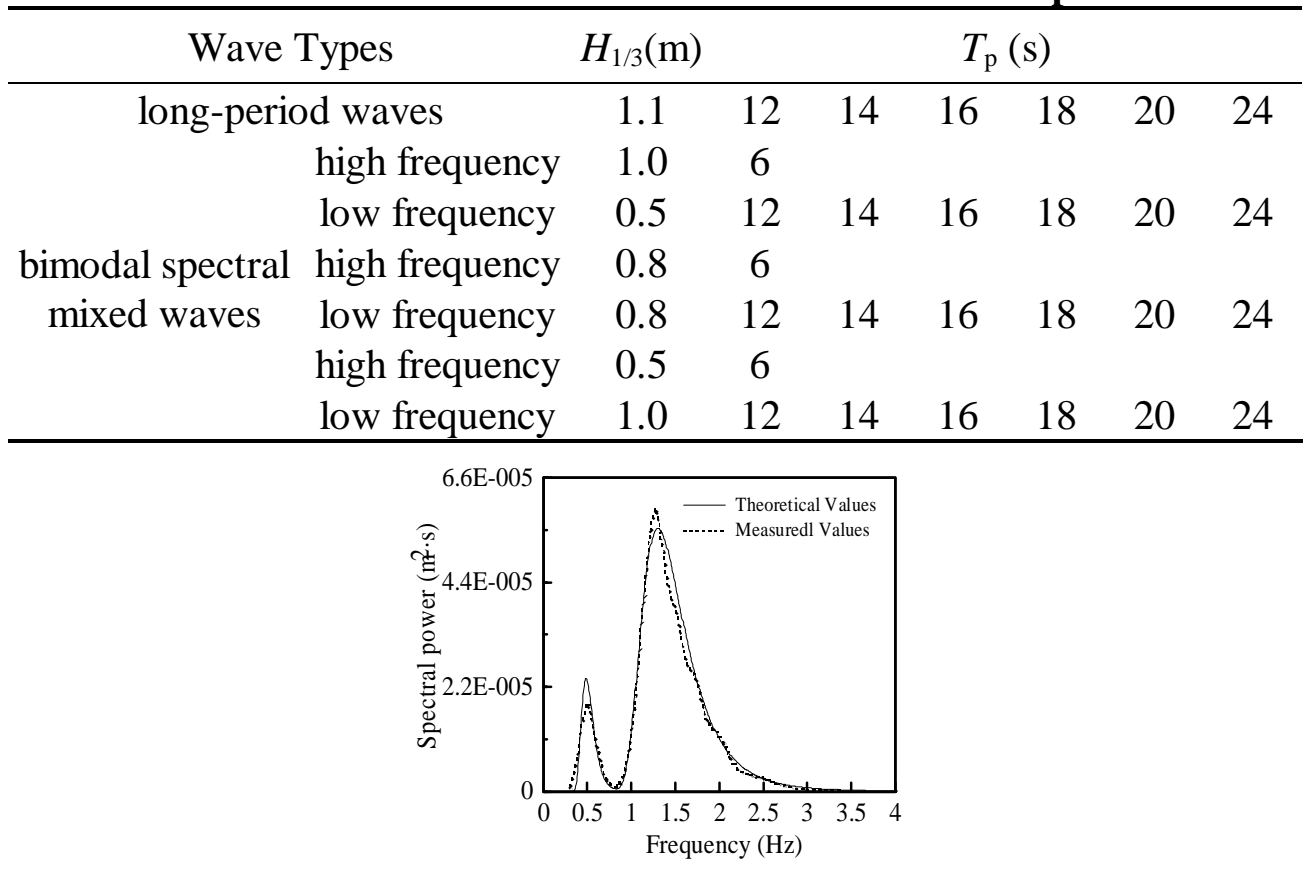

Fig. 4 Comparison of Simulated and Measured Values of Bimodal Spectral Mixed Waves (Low-frequency Waves: $H_{s}=0.5 m, T=16 \mathrm{~s}$; High-frequency Waves: $H_{s}=1.0 m, T=6 \mathrm{~s}$ )

\section{Results and discussion}

In Fig. 5 and Fig. 6, the experimental result of the mooring ship's movements in mixed waves is compared to the one of the same ship's movements in long-period waves on condition that the total energy is the same and the period of low-frequency spectral peak is set within the range from 12 to $24 \mathrm{~s}$. It should be noted that the horizontal axis in both Figure 5 and 6 is set for the period of low-frequency spectral peak of mixed waves. Besides, the period of low-frequency spectral peak of mixed waves and the period of long-period waves can be used for comparison directly.

It can be seen from Fig. 5 and Fig. 6 that the mooring ship's movements (except the component movement of pitch) will increase with the rising of the ratio of low-frequency energy in mixed waves on the condition that the total energy of mixed waves equals to the one of long-period waves. However, the low-frequency spectral peak periods of the mooring ship's motions changes basically the same way in the three kinds of transverse mixed waves with different ratios of high-frequency and low-frequency energy of the mixed waves. Besides, its changing patterns are also consistent with the ones of the 
mooring ship's movements in long-period waves when the wave peak period changes. In other words, with the changing of the low-frequency spectral peak period of mixed waves within the default test value range, the changing patterns of a mooring ship's movements is independent of the ratio of high-frequency and low-frequency energy of mixed waves. Such a phenomenon is quite similar to the situation that a mooring ship's movements changing patterns with the changing of spectral peak period of waves in different transverse long-period waves with different wave heights are independent of the value of wave heights ${ }^{[11]}$.
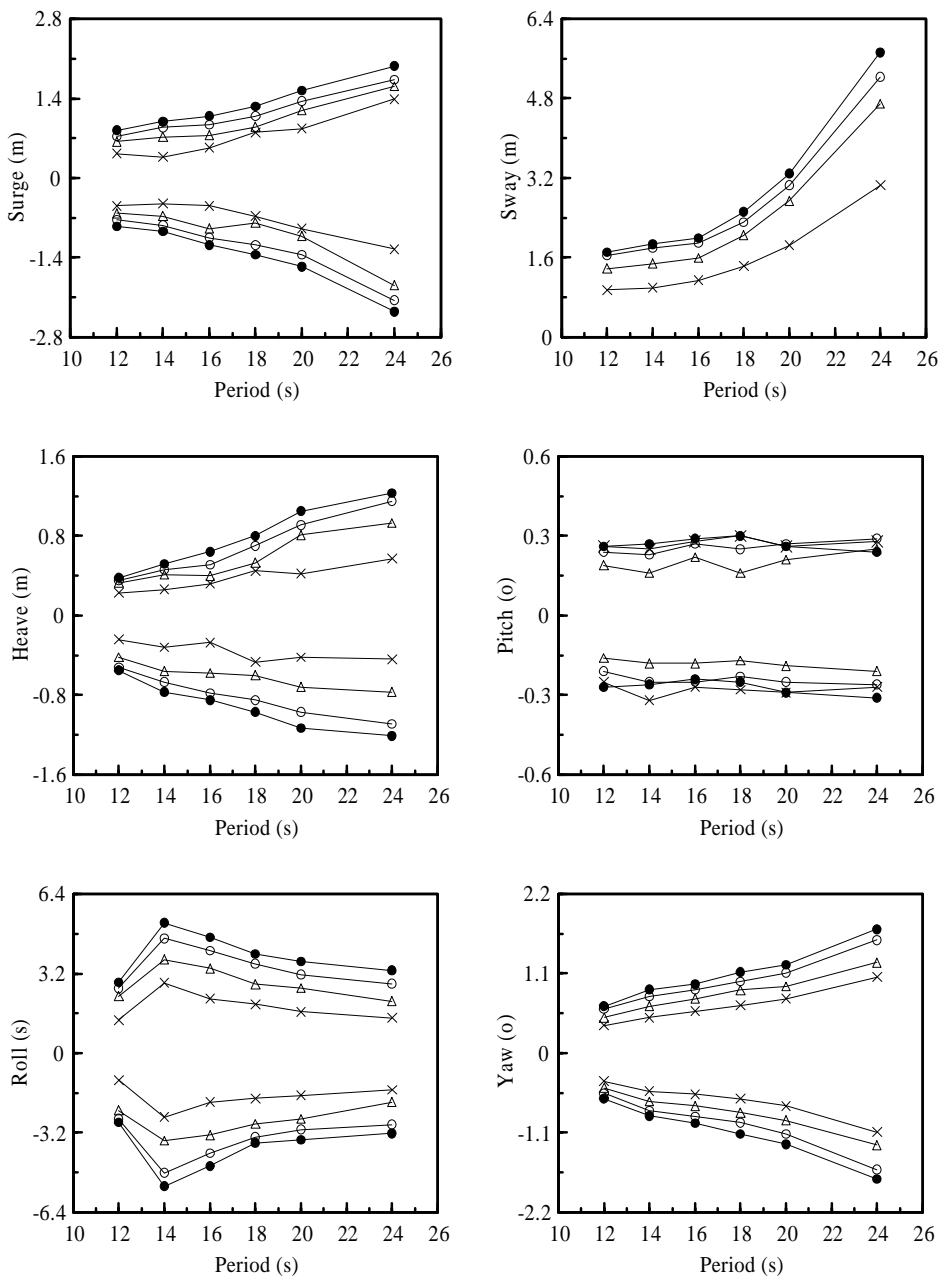

( Legend : -•-long-period waves ;

- $-80 \%$ contribution of the low-frequency wave energy to the mixed waves ;

$-\square-50 \%$ contribution of the low-frequency wave energy to the mixed waves ;

$-x-20 \%$ contribution of the low-frequency wave energy to the mixed waves )

\section{Fig. 5 Comparison of Values of Movements of the Mooring Ship in Mixed Waves and Long Waves under the Ballasted Condition}

As also shown in Fig. 5 and Fig. 6, when the low-frequency wave energy accounts for $20 \%$ of the total, the value of amplitude of the movements of a mooring ship (except the component movement of pitch) in mixed waves is much smaller than that in long-period waves. The minimum values of the movements of a mooring ship in mixed waves are 0.4 times of those in long-period waves, and the maximum values are 0.71 times of those in long-period waves. In most cases, the movements of a mooring ship in mixed waves are within the range from 0.5 to 0.6 times of those in long-period waves.

When the low-frequency wave energy accounts for $50 \%$ of the total, the values of amplitude of the movements of a mooring ship (except the component movement of pitch) in mixed waves are a little higher than the above mentioned $20 \%$ situation. The minimum values of the movements of a mooring 
ship in mixed waves are 0.63 times of those in long-period waves, and the maximum values are 0.96 times of those in long-period waves. In most cases, the movements of a mooring ship in mixed waves are within the range from 0.7 to 0.8 times of those in long-period waves.

As the ratio of the low-frequency wave energy increases until it accounts for $80 \%$ of the total, the differences between the values of the movements of a mooring ship (except the component movement of pitch) in both mixed waves and long-period waves become small. The minimum values of the movements of a mooring ship in mixed waves are 0.82 times of those in long-period waves, and the maximum values are almost the same with those in long-period waves. In most cases, the movements of a mooring ship in mixed waves are within the range from 0.85 to 0.95 times of those in long-period waves.
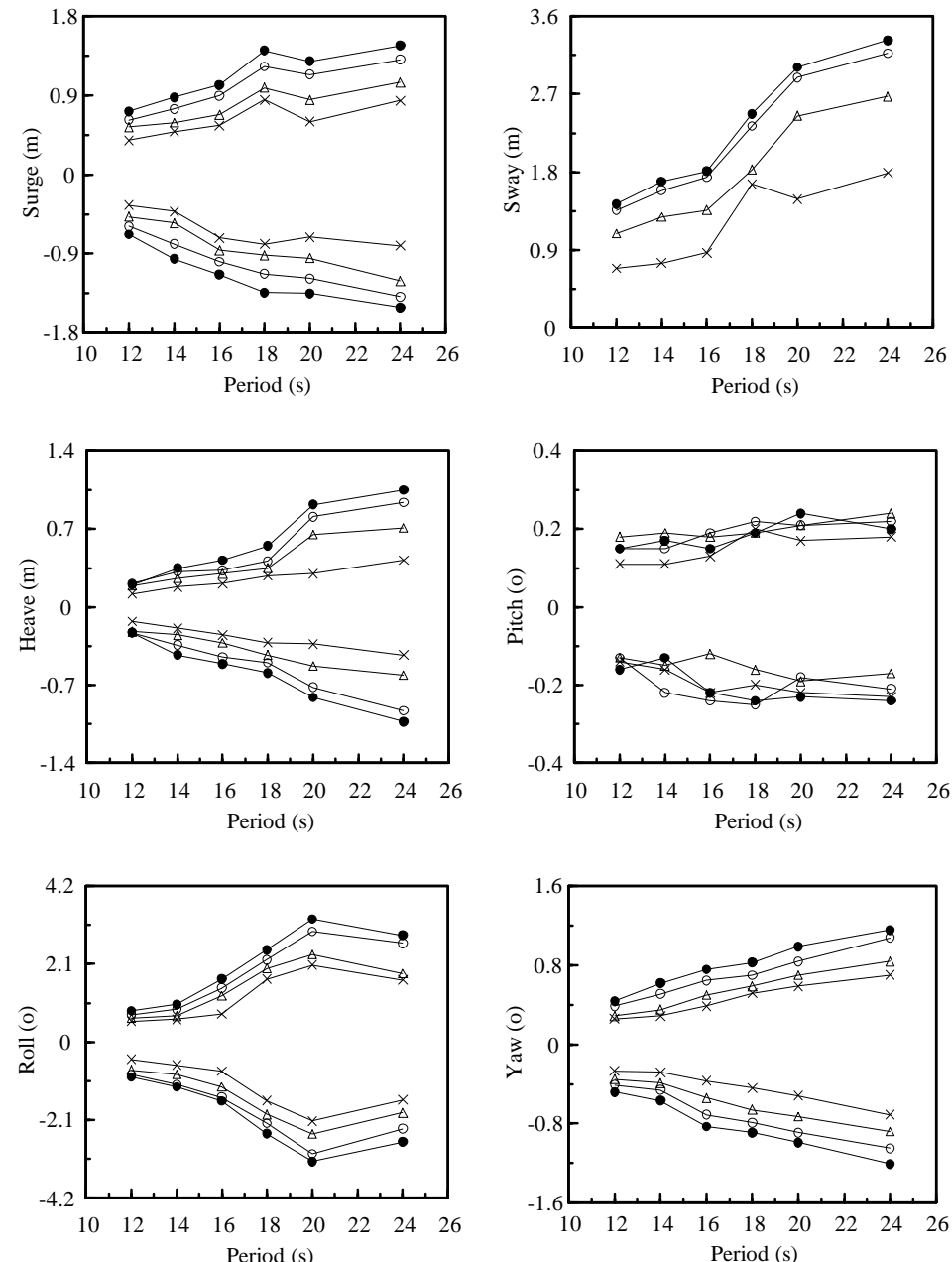

(Legend as in Fig.5)

Fig. 6 Comparison of Values of Movements of the Mooring Ship in Mixed Waves and Long Waves under the Laden Condition

\section{Conclusions}

In this paper, a comparative study of a mooring ship's motion was carried out in the three kinds of transverse mixed waves with different ratios of high-frequency and low-frequency energy of the mixed waves as well as in long-period waves on the condition that the total wave energy for each time is the same. According to the specific requirement especially the default test value range, conclusions were drawn as follows:

(1) With the changing of the low-frequency spectral peak periods, the motions of a mooring ship change basically the same way in the three kinds of transverse mixed waves with different ratios of high-frequency and low-frequency energy as well as in the transverse long-period waves, which are independent of the ratios of high-frequency and low-frequency energy of mixed waves. 
(2) The ratio of the low-frequency energy of mixed waves has a ruling effect on the motions of a mooring ship (except the component movement of pitch) in bimodal spectral mixed waves. In general, when the low-frequency wave energy accounts for $20 \%$ of the total, the movements of a mooring ship in mixed waves are within the range from 0.5 to 0.6 times of those in long-period waves; when the low-frequency wave energy accounts for $50 \%$ of the total, the movements of a mooring ship in mixed waves are within the range from 0.7 to 0.8 times of those in long-period waves; when the low-frequency wave energy accounts for $80 \%$ of the total, the movements of a mooring ship in mixed waves are within the range from 0.85 to 0.95 times of those in long-period waves.

\section{Acknowledgements}

This research was financially supported by Liaoning Provincial Department of Education Fund under Grant No. L2014280, as well as the Program of Talent Introduction of Dalian Ocean University.

\section{References}

[1] BS 6349-1: 2000 Maritime Structures -Part 1: Code of Practice for General Criteria [S]. UK, 2000, pp. 77.

[2] PIANC. Criteria for Movements of Moored Ships in Harbours: a Practical Guide [R]. Report of Working Group NO. 24 of the Permanent Technical Committeell . Brussel, PIANC, 1995.

[3] Guedes Soares, C. On the Occurrence of Double-peaked Wave Spectra [J]. Ocean Engineering, 18 (1991): 167-171.

[4] Petya G. Petrova, C. Guedes Soares. Wave Height Distributions in Bimodal Sea States from Offshore Basins [J]. Ocean Engineering, 38 (2011) 658-672.

[5] Petya G. Petrova, C. Guedes Soares. Probability Distributions of Wave Heights in Bimodal Seas in an Offshore Basin [J]. Applied Ocean Research, 31 (2009) 90-100.

[6] YANG Xian-zhang. Long-period Wave Characteristics and Its Effect on the Dynamic Characteristics of Mooring Ships [J]. Harbour Engineering, 6 (1989) 37-43. (in Chinese)

[7] Van der Molen W., Ligteringen H.J., Van der Lem C.,et al. Behavior of a Moored LNG Ship in Swell Waves [J]. Journal of Waterway, Port, Coastal, and Ocean Engineering, ASCE, 129 (2003) $15-21$.

[8] Van der Molen W., MONARDES P., Van Dongeren A. R. Numerical Simulation of Long-Period Waves and Ship Motions in Tomakomai Port Japan [J]. Coastal Engineering Journal, 48 (2006) 59-79.

[9] Sakakibara S., Saito K. and Kubo M. A Study on Long-Period Moored Ship Motions in a Harbor Induced by a Resonant Large Roll Motion under Long-Period Waves [C]. Proceedings of the Eleventh International Offshore and Polar Engineering Conference, Stavanger, Norway, 2001, pp. 326-333.

[10] Shi Xian-ying, Zhang Ning-chuan, Yang Yang, and Huang Yu-xin. Experimental Study on the Motions of a Mooring Ship in Mixed Waves. Journal of Marine Science and Technology, 21 (2013) 453-459.

[11] Shi Xian-ying, Zhang Ning-chuan, Chen Chang-ping, Jiang Heng-zhi, and Cui Lei. Experimental Study of Characteristics of Motions of a Large Mooring Ship in Long-period Waves. Journal of Marine Science and Technology, 22 (2014) 240-246.

[12] JTJ/T 234-2001, Wave Model Test Regulation, Beijing, China, 2001, pp. 6. (in Chinese) 